\title{
LA GESTIÓN SOCIAL DEL SÍLEX MELADO DURANTE EL NEOLÍTICO MEDIO EN EL NORDESTE DE LA PENÍNSULA IBÉRICA
}

\author{
LA GESTION SOCIALE DU SILEX BLOND DURANT LE NÉOLITHIQUE MOYEN AU \\ NORD-EST DE LA PÉNINSULE IBÉRIQUE
}

\author{
XAVIER TERRADAS $(*)$ \\ JUAN FRANCISCO GIBAJA $(* *)$
}

\begin{abstract}
RESUMEN
En este artículo presentamos la reconstrucción de las estrategias desarrolladas en la gestión de un recurso mineral concreto, el sílex melado presumiblemente procedente del valle del Ródano, por los grupos humanos que durante el Neolítico medio habitaron el nordeste peninsular. A partir de los restos líticos recuperados en varios yacimientos catalanes constatamos una fragmentación en el tiempo y el espacio de los procedimientos técnicos aplicados en la explotación de esta materia prima de origen lejano, orientada hacia la generación de una mayor rentabilidad de las actividades económicas desarrolladas. Sin embargo, esta rentabilidad entra en contradicción con el fin al que fueron destinados una gran parte de los productos obtenidos, como elementos de ajuar en inhumaciones individuales conocidas como sepulcros de fosa, al tratarse de productos no utilizados o todavía operativos desde un punto de vista funcional.
\end{abstract}

\section{RÉSUMÉ}

Nous preséntons ici la reconstruction des stratégies mises en oeuvre dans la gestion d'un ressource minéral concret, le silex blond présumablement procédant de la vallée du Rhône, par les groupes humaines que pendant le Néolithique moyen habitèrent le nord-est de la Péninsule ibérique. A partir des vestiges lithiques récupérés dans plusieurs sites catalanes on constate une fragmentation dans

(*) Laboratorio de Arqueología. Institución Milà y Fontanals. CSIC. Egipciaques 15. 08001 Barcelona. Correo electrónico: terradas@bicat.csic.es

(**) Museu d'Arqueologia de Catalunya-Barcelona. Passeig de Santa Madrona, 39-41. Parc de Montjuïc. 08038 Barcelona. Correo electrónico: jfgibaja@teleline.es

Recibido: 4-VI-2001; aceptado: 13-IX-2001. le temps et l'espace des procédés techniques mises en oeuvre par l'exploitation de cette matière première d'origine lointaine, dirigée vers l'obtention d'une plus grande rentabilité des activités économiques. Néanmoins, cette rentabilité est en contradiction avec la destination d'une grande partie des produits obtenus, encore opérati$f s$ du point de vue fonctionnel ou pas utilisés, vers des inhumations individuelles connues comme sépulcres de fosse.

Palabras clave: Gestión de los recursos minerales. Sílex melado. Neolítico medio. Nordeste Península Ibérica. Talla laminar por presión. Tratamiento térmico. Sepulcros de fosa.

Mots-clés: Gestion des ressources minérales. Silex blond. Néolithique moyen. Nord-est Péninsule ibérique. Débitage laminaire par pression. Traitement thermique. Sépulcres de fosse.

\section{INTRODUCCIÓN}

Tradicionalmente, la aparición en distintos contextos arqueológicos neolíticos del nordeste de la Península ibérica de núcleos y distintos productos laminares obtenidos a partir de la explotación de bloques de sílex melado ha sido considerada como un elemento extraño. La ausencia en el nordeste peninsular de este tipo de materia prima y, por ende, el desconocimiento de su origen, así como su asociación casi exclusiva a contextos funerarios, son aspectos que han contribuido todavía más a enfatizar esta cuestión. De este modo, se ha otorgado a estos restos una fuerte carga simbólica e ideológica, aún sin intentar profundizar en los procesos y mecanismos que posibilitaron su presencia en los contextos en que fueron recuperados. 
Otro tanto sucede con el tratamiento térmico de rocas silíceas para la producción de instrumental lítico. Este procedimiento técnico, comúnmente utilizado en determinados contextos cronológicos y geográficos, ha sido abordado únicamente desde aquellos aspectos concernientes a los efectos físico-químicos sufridos por las materias primas transformadas, a su identificación a nivel empírico y a su repercusión en la producción lítica. Salvo algunas excepciones, como por ejemplo la relativa al Chasséen francés (Binder, 1984; 1991; Binder y Gassin, 1988; Binder et al., 1990; Gassin, 1996; Lea, 1997), esta situación ha conducido a estudiar el tratamiento térmico como un fenómeno en sí mismo, olvidando que no es más que un procedimiento técnico empleado para la producción de determinados instrumentos líticos bajo la aplicación de sistemáticas de talla y formalización concretas. Asimismo, en la literatura arqueológica este recurso técnico raramente aparece como tal, integrado en un marco tecnológico, económico y social más amplio.

Por todo ello, los objetivos del presente artículo se centran en intentar solventar dichos aspectos, reconstruyendo las estrategias diseñadas en la gestión de un recurso mineral concreto (el llamado "sílex melado"), por parte de los grupos humanos del Neolítico medio que desarrollaron su actividad social en el noreste peninsular. A grandes rasgos, asimilamos esta zona geográfica al territorio que en la actualidad correspondería administrativamente a Catalunya (1).

\subsection{El Neolítico medio en el nordeste de la Península ibérica}

Tradicionalmente, y todavía hoy en día, el Neolítico medio en Cataluña (4300-3400 cal BC) ha sido asociado al fenómeno englobado bajo el término de "cultura de los sepulcros de fosa" por P. Bosch Gimpera (1919). La documentación de un número importante de contextos funerarios atribuibles a este período cronológico, en contraste con la práctica ausencia de asentamientos coetáneos, ha contribuido a acentuar todavía más tal asimilación. Dicho fenómeno no sólo abarcaba el tipo de estructura o arquitectura funeraria, sino también otros

(1) Estos objetivos forman parte de un proyecto de investigación más amplio, que constituye la tesis del tercer ciclo universitario de uno de nosotros (JFG). elementos asociados a la misma, como el número y disposición de los cadáveres inhumados (normalmente uno sólo y en posición estirada o supina), o el ajuar depositado junto a los mismos (núcleos y láminas de sílex, hachas y azuelas de roca pulimentada, recipientes cerámicos sin motivos decorativos y/o con boca cuadrada, cuentas de piedra, punzones de hueso, colmillos de jabalí, etc.).

Desde entonces ha sido constante la aparición de hipótesis relativas a su origen, cronología, extensión geográfica y filiación con otras manifestaciones arqueológicas similares. Aunque inicialmente se consideró que estaba estrechamente vinculada a la "cultura de Almería" (Serra Ràfols, Pericot, Almagro, citados en Muñoz, 1965), posteriormente otros investigadores le atribuyeron una mayor relación con facies culturales del mediterráneo occidental: Cortaillod, Lagozza y Chasséen (Tarrade1l, 1960; Ripoll y Llongueras, 1963; Muñoz, 1965).

A pesar de que actualmente se considera que, efectivamente, los lazos de unión con las manifestaciones arqueológicas aparecidas en el sur de Francia son muy estrechos (Llongueras et al., 1986; Martín y Tarrús, 1991), las hipótesis sobre este tema han ido variando en función de nuevos estudios y excavaciones. Dichas variaciones también se han establecido gracias a las numerosas dataciones absolutas llevadas a cabo en estos dos últimos decenios (Muñoz, 1965; Martín, 1986-1989; Mestres y Martín, 1996).

A partir de los años 70-80, la renovación metodológica asociada a la aparición de la New Archaeo$\operatorname{logy}$, así como la influencia ejercida en Cataluña por investigadores foráneos, supusieron el desarrollo de una metodología de campo mucho más cuidadosa, la realización sistemática de dataciones absolutas, así como la aplicación de técnicas analíticas relativas a la reconstrucción paleoambiental y de las actividades subsistenciales.

De este modo, la caracterización del Neolítico medio en el nordeste peninsular ha sido establecida en base a los siguientes criterios (AA.VV., 1982; 1992; 1996; Bernabeu y Orozco, 1999):

- la consolidación de una base económica fundamentalmente agropecuaria,

- la explotación con carácter no estrictamente subsistencial de materias primas concretas (variscita (2), sílex melado, ciertas rocas me-

(2) Es en este momento cuando se desarrolla con mayor intensidad la extracción de este mineral en el complejo minero de Gavà (Barcelona), (Villalba et al., 1986; Bosch et al., 1996; Bosch y Estrada, 1998).

T. P., 59, n. ${ }^{\circ} 1,2002$ 
tamórficas para la manufactura de objetos pulimentados y, excepcionalmente, obsidiana),

- la organización de espacios sepulcrales específicos.

Pese a la aparente unidad reflejada por el registro material de los yacimientos catalanes atribuibles a este período, algunos autores han convenido en aislar geográficamente tres tipos de modelos socioeconómicos, diferenciables en base a la organización de los espacios funerarios, los ecosistemas explotados, así como las estrategias económicas desarrolladas sobre los recursos ofrecidos por dichos ecosistemas (Martín y Tarrús, 1995). Inicialmente, M. Cura $(1975 ; 1976)$ propuso la existencia del Solsonià, con sepulturas en cista, y del Vallesià, con enterramientos en fosa, y posteriormente J. Tarrús (1987) estableció el Empordanès, asociado a sepulcros de corredor.

Sin embargo, estos criterios no son tan discriminantes como en principio se suponía, al documentarse conjuntamente en un mismo ámbito geográfico distintos tipos de estructura o arquitectura funeraria (3). Además, en estas dos ultimas décadas, se ha demostrado que las inhumaciones individuales en fosa o en cista no son exclusivas del Neolítico medio y períodos subsiguientes, puesto que el descubrimiento y la datación de yacimientos recientes (4), así como la revisión de materiales procedentes de excavaciones antiguas, han permitido demostrar su aparición en cronologías anteriores (Molist et al., 1987; Mestres, 1988-1989; Granados et al., 1993; Vignaud, 1995; Bosch, 1995).

\subsection{La problemática del sílex melado}

El tipo de rocas silíceas explotadas para la producción lítica, y más concretamente el sílex melado de origen supuestamente alóctono, ha constituido uno de los elementos definitorios y distintivos del Neolítico medio en los contextos arqueológicos catalanes, llegando a constituir un verdadero fósil director para este período cronológico. La alta representatividad en contextos funerarios de esta materia prima, así como de productos obtenidos a

(3) Dicha situación también se da en el sur de Francia durante el Chasséen (Boujot et al., 1991).

(4) Camp del Ginèbre 528 (Caramany, Pyrénees Orientales) en Francia, así como Font de la Vena y El Padró (Tavertet, Barcelona), Sant Pau del Camp (Barcelona), Hort d'en Grimau (Castellví de la Marca, Barcelona), Barranc d'en Fabra y Pla d'Ampúries (Amposta, Tarragona), entre otros. partir de su explotación, ha llevado a algunos investigadores a plantear la posibilidad de que el sílex melado tuviese un valor estético o simbólico (Binder, 1984; Gassin, 1993; Perlès, 1992).

Tanto es así, que la menor presencia de este tipo de roca a medida que transcurre el IV milenio $\mathrm{cal}$ $\mathrm{BC}$ ha sido tomada como un elemento de ruptura en las redes de intercambio a larga distancia que se habían consolidado durante el Neolítico medio, y por ende, con el establecimiento de un nuevo período crono-cultural: el Neolítico Final, caracterizado por la denominada "cultura de Veraza" (Martín, 1992).

Sin embargo, la presencia de esta materia prima de naturaleza mineral en el Neolítico medio del nordeste peninsular es también uno de los aspectos relacionados con la producción y reproducción social que han sido menos estudiados. Ante la ausencia de marcos teórico-metodológicos explícitos bajo los que se analice la procedencia de este tipo de rocas silíceas, sorprenden las importantes y relevantes interpretaciones que se han hecho a partir de su supuesto origen foráneo, como la diferenciación social en el Neolítico medio a partir del control de ciertos recursos minerales tales como el propio sílex melado o la variscita (Pou et al., 1996; Martí et al., 1997).

En este sentido, en Cataluña, el único criterio que ha sido utilizado para otorgar tal entidad al sílex melado ha sido su coloración y aspecto. Los atributos técnicos de los distintos productos obtenidos a partir de su explotación, así como la reconstrucción tecnológica de dichos procesos apenas han tenido protagonismo, aún observando que se trataba de un tipo de materia prima rara y de muy buena calidad, transformada preferentemente a partir de sistemáticas de talla específicas (notablemente mediante la presión para la producción de soportes laminares) (Terradas y Gibaja, 2001).

Con respecto a su origen geográfico las propuestas hipotéticas que se han barajado no concluyen datos precisos, defendiendo una procedencia foránea sin más, si bien una parte importante de los trabajos publicados tienden a situar sus zonas de aprovisionamiento en distintos puntos del sudeste de Francia (Vaquer, 1990). En este sentido, destaca el trabajo publicado recientemente por D. Binder (1998) quien, a partir de una prospección temática de ámbito provenzal (Vaucluse, Bouches-du-Rhône, Var, Alpes-de-Haute-Provence, Alpes-maritimes), documenta más de 400 estaciones desde el punto de vista litológico y fija su origen geológico 
en las formaciones del Cretáceo inferior (Bédoulien) de la alta Provenza.

Sin embargo, es necesario matizar que gran parte de estos trabajos son puntuales, llevados a cabo a partir de muestras arqueológicas escasas, en marcos de estudio de alcance geológico y geográfico limitado, sin que se haya logrado desarrollar con éxito un programa de investigación a largo plazo que contemple una completa reconstrucción de las estrategias implementadas en la gestión de los recursos minerales, así como una interpretación a partir de su dinámica cronológica y geográfica.

\subsection{Principios de la producción de soportes laminares por presión}

A partir de los resultados disponibles hasta el momento en el nordeste peninsular, los bloques de sílex melado fueron explotados exclusivamente para la obtención de soportes laminares mediante la aplicación de esta sistemática de talla. Se caracteriza por seguir un método preconcebido con el objetivo de obtener productos laminares seriados, y entre sus particularidades podríamos destacar la precisión y previsibilidad en lo que respecta a la dinámica de explotación de los núcleos, así como a la obtención de láminas y/o laminillas. Dichas propiedades ofrecen la posibilidad de obtener una producción estandarizada o ajustada a unas normas técnicas y morfológicas precisas, hecho que permite asegurar una rentabilidad importante, tanto desde el punto de vista del ahorro de materia prima que supone como de la cantidad de productos obtenidos.

Los primeros indicios arqueológicos de su práctica se documentan entre los grupos cazadores-recolectores del área siberiano-mongola, ahora hace unos 25.000 años (Inizan, 1991), generalizándose durante el fin del Pleistoceno en gran parte del continente asiático y a inicios del Holoceno en el Viejo Mundo (Tixier, 1984).

La comprensión de su dinámica y reglas de funcionamiento viene dada a partir de su replicación experimental (Pelegrin, 1984a; 1984b; 1984c; 1988; Texier, 1982; 1983; 1984), en base a los trabajos iniciados por D.E. Crabtree y J. Tixier en los años 60.

En todos estos trabajos se confiere la máxima importancia a la fase de configuración del núcleo (Crabtree, 1968; Texier, 1982; Pelegrin, 1984a; Tixier, 1984; Torrence, 1984; Binder, 1991; Inizan,
1991; Volkov y Guiria, 1991; Lea, 1997), puesto que dicha sistemática de talla sólo puede ser desarrollada bajo un reducido número de morfologías estereotipadas. Dicha configuración predeterminará las características geométricas del volumen a explotar y de la superficie de lascado, así como la morfometría de los productos obtenidos, y únicamente podrá llevarse a cabo bajo dos abstracciones volumétricas concretas (5):

- cónica, con una superficie de lascado de sección ojival y un plano de presión de sección oval o circular, generando productos laminares de morfología triangular;

- paralelepípeda, con una superficie de lascado y un plano de presión de sección rectangular, ge-nerando productos laminares de morfología rectangular.

De este modo, la regularidad geométrica de la morfología configurada constituye una obligación técnica crucial y, al mismo tiempo, una limitación para su óptima explotación. En este sentido, se precisa una materia prima homogénea y de buena calidad, que puede ser mejorada mediante un tratamiento térmico previo (6). Se trata pues de un método muy rígido en el que la aplicación de cualquier mecanismo de reparación de errores y/o accidentes es muy costosa, tanto desde el punto de vista de la materia prima a sacrificar como de la reducción de la productividad del núcleo. Por este motivo, aunque la configuración de dichos volúmenes pueda albergar más de un frente activo de explotación, su relación será sucesiva, nunca simultánea ni complementaria, generando exclusivamente explotaciones unipolares.

(5) Si bien la técnica característica de esta sistemática de talla corresponde a la presión, la configuración del bloque de materia prima puede realizarse mediante diversas técnicas (percusión directa/indirecta con percutor blando/duro).

(6) Es conveniente matizar la diferencia entre los conceptos de tratamiento térmico y alteración térmica, puesto que con frecuencia son usados indistintamente provocando confusiones entre ambos. Entendemos que el tratamiento térmico corresponde al procedimiento técnico empleado por ciertas sociedades prehistóricas e históricas con el objetivo de mejorar las aptitudes de ciertas materias primas en la producción lítica, obteniendo como resultado un aumento en la rentabilidad de su explotación. Consecuentemente, las alteraciones térmicas corresponden a las modificaciones sufridas por las distintas materias primas a lo largo del proceso anterior. Estas alteraciones pueden ser resultado de un proceso intencionado, siguiendo las pautas inherentes al tratamiento térmico sin que el agente social que interviene en este caso pueda evitarlo, o bien una consecuencia accidental (sobreexposición térmica u horaria), casual (contacto con un foco calórico debido al azar), o debida a procesos postdeposicionales (combustión de hogares sobre restos líticos ya depositados) (Terradas y Gibaja, 2001). 
Aparte de las premisas técnicas mencionadas anteriormente, la precisión en la elección del punto exacto de aplicación de la fuerza (presión) y de la dirección de la misma favorecerá el desarrollo de un orden sistemático en las extracciones, con tendencia a obtener productos laminares de sección trapezoidal.

De este modo, el emplazamiento del punto de aplicación de la fuerza debe provocar y controlar un tipo de ruptura frágil, en función de la proximidad y la geometría de la superficie de lascado. En este sentido, la posible abrasión de las cornisas del frente de explotación tendrá una doble función:

- evitar el deslizamiento de la punta del instrumento presionador con el objetivo de transmitir la fuerza en las mejores condiciones posibles,

- facilitar la apertura de una fisura mediante el desgaste previo del plano de presión (desarrollo de conos de presión incipientes).

Esta precisión sería inútil si no se procediera a inmovilizar el núcleo durante su explotación, puesto que el más mínimo movimiento durante la extracción de un producto laminar puede provocar ondulaciones marcadas en la cara inferior de los productos desprendidos, así como en sus respectivos negativos en la superficie de lascado del núcleo. A su vez, en función del mecanismo empleado en su fijación, pueden producirse accidentes característicos, como láminas sobrepasadas y/o fracturadas, de todos modos frecuentes en este tipo explotación.

La preparación del plano de presión tiene una importancia menor e incluso, con frecuencia, puede ser ubicado en el último momento de la fase de configuración, ya sea sobre una superficie natural (córtex, plano de debilidad interna, fractura), o sobre un plano creado mediante una plataforma lisa (negativo de una gran extracción) o facetada (extracciones centrípetas).

Los criterios que permiten reconocer los productos obtenidos mediante la aplicación de esta sistemática de talla son:

- la regularidad en el conjunto de productos obtenidos, que presentan una tendencia rectilínea y paralela en bordes y aristas, dejando en los núcleos negativos de extracciones igualmente rectilíneas y regularmente paralelas.

- la ausencia de ondulaciones marcadas en su cara inferior.
- una sección sagital poco arqueada, llana en dos terceras partes de su longitud y con una curvatura distal característica.

- su débil espesor.

- la menor amplitud del talón respecto a la del resto del producto, que alcanza su máxima amplitud en la zona proximal.

\section{LA PRODUCCIÓN DE SOPORTES LAMINARES POR PRESIÓN Y SU FUNCIÓN EN EL NEOLÍTICO MEDIO DEL NORDESTE PENINSULAR}

Como hemos mencionado en la introducción del presente artículo hemos tomado como ejemplo de aplicación la producción lítica llevada a cabo por las comunidades del Neolítico medio en el nordeste peninsular (Cataluña), si bien nos hemos ceñido a la producción de soportes laminares por presión sobre ciertas rocas silíceas (sílex melado). La reconstrucción de dicha sistemática de talla se ha llevado a cabo reconstruyendo los distintos procesos y etapas inherentes al proceso de producción lítica (Terradas, 1995; 1996; 1998).

Las colecciones empleadas para proceder a esta reconstrucción proceden de los contextos sepulcrales de Bòbila Madurell (Sant Quirze del Vallès, Barcelona) y Camí de Can Grau (La Roca del Vallès, Barcelona), (Clemente y Gibaja, 1998; Gibaja 1997; Gibaja y Clemente, 1996; Gibaja et al., 1997), junto con la recuperada en el asentamiento al aire libre de Ca n'Isach (Palau-Saverdera, Girona)(Gibaja, e.p.) (Fig. 1). Si bien la aportación de cada yacimiento es diferente en función de la com-

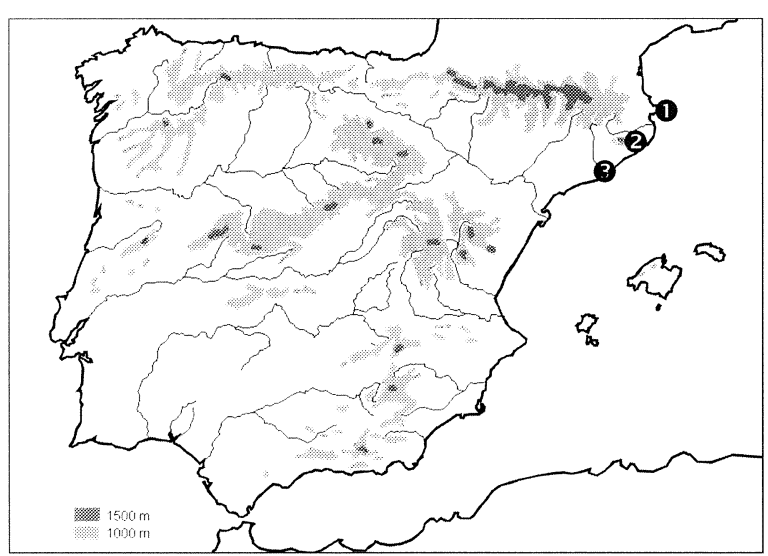

Fig. 1. Situación de los contextos arqueológicos del Neolítico medio del nordeste peninsular. 1 Can'Isach; 2 Camí de Can Grau; 3-Bòbila Madurell. 


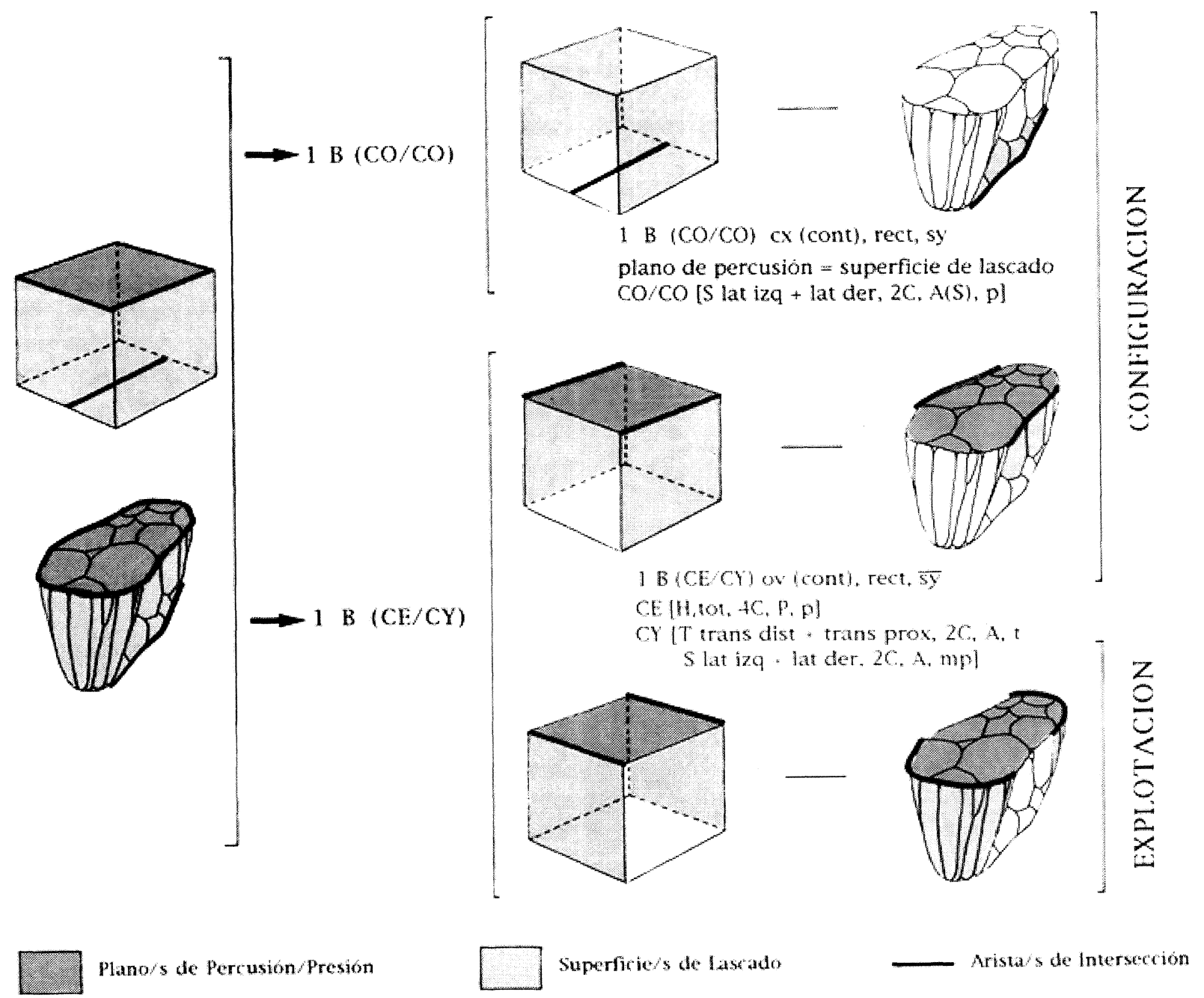

Fig. 2. Esquema de la dinámica de configuración y explotación de los bloques de materia prima para la producción de soportes laminares por presión.

posición cualitativa y cuantitativa del conjunto lítico recuperado, su análisis global nos ha permitido observar que la explotación de los bloques de sílex melado se desarrolló siempre siguiendo una misma dinámica (7).

\subsection{La configuración de las bases de materia prima}

En el caso que nos ocupa, esta etapa concluye con la conformación de los núcleos a partir de la

(7) Dinámica que es similar a la registrada en algunos yacimientos del Chasséen francés, como la Grotte de la Cabre en Saint Raphaël -Var- (Lea, 1997) o los talleres de Villelonguedels-Monts -Pyrénees Orientales- (Briois et al., 1990). transformación de los bloques de materia prima, obteniendo de este modo morfologías en un estado óptimo para iniciar su explotación con el objetivo de obtener una producción seriada y estandarizada de soportes laminares. La implementación de los elementos estructurales de estos núcleos se realiza de la siguiente manera (Fig. 2):

- Plano de presión (plano de simetría horizontal): de acuerdo con las normas que rigen esta sistemática de talla (cf. supra), su preparación es escasa, correspondiendo normalmente a una gran extracción (muchas veces mediante el empleo de un percutor duro), o al aprovechamiento de una fractura ya existente. En otras ocasiones dicho plano tiene un acondicionamiento más cuidado, a partir de la realización de extracciones con dirección cen- 
trípeta, pudiéndose emplear tanto un percutor duro como blando.

- Superficie/s de lascado principal/es (plano/s de simetría transversal/es): denominada como principal puesto que su rol consistirá en propiciar la obtención de los soportes laminares que justifican el desarrollo de esta sistemática de talla. Su preparación es muy cuidada, y se consigue a partir de la preparación de una cresta mediante el empleo de la técnica de la percusión blanda, y la extracción, ya mediante la presión, de una lámina en cresta así como de otros productos laminares iniciales, de sección triangular.

- Superficie/s de lascado secundaria/s (plano/s de simetría sagital/es): aunque en esta sistemáti-ca de talla adquieran un rol complementario de la superficie descrita anteriormente, su desarrollo posibilita el mantenimiento de la/s superfi$\mathrm{cie} / \mathrm{s}$ de lascado principal/es y, en menor grado, del plano de presión. Al mismo tiempo, constituye un recurso técnico al que recurrir en el caso de reparación de errores o de accidentes en ambas superficies. Su preparación y mantenimiento se realiza exclusivamente mediante el uso de un percutor blando.

La interacción que se genera entre todos estos elementos dentro de la concepción volumétrica que rige la sistemática de talla en cuestión, otorga a los núcleos un volumen cónico, con una sección ojival (observada según el plano de simetría transversal y/o sagital) y oval (observada desde el plano de simetría horizontal) (Figs. 3 y 4 ).

El tipo de transformación llevado a cabo en cada uno de estos planos puede caracterizarse en base al ángulo de combinación establecido entre la zona transformada y el plano de orientación del núcleo (8). La combinación entre estos tres elementos estructurales (plano de presión, superficie/s de lascado y arista de intersección) es la que permitirá caracterizar el tipo de concepción volumétrica que dirige la dinámica de transformación del bloque de materia prima en núcleo y la explotación del mismo, tal como queda esquematizado en la figura $2(9)$.

(8) Respecto a la orientación del núcleo, hemos convenido en situar en el plano de simetría horizontal el plano teórico que forma la arista de intersección entre el plano de presión y la superficie de lascado del núcleo (Terradas, 1995).

(9) Una mayor información sobre la metodología empleada en el análisis de los caracteres morfotécnicos de los distintos productos líticos y en la reconstrucción de una sistemática de talla dentro del proceso de producción lítica puede ser obtenida en otros trabajos más generales (Terradas, 1995; 1996).

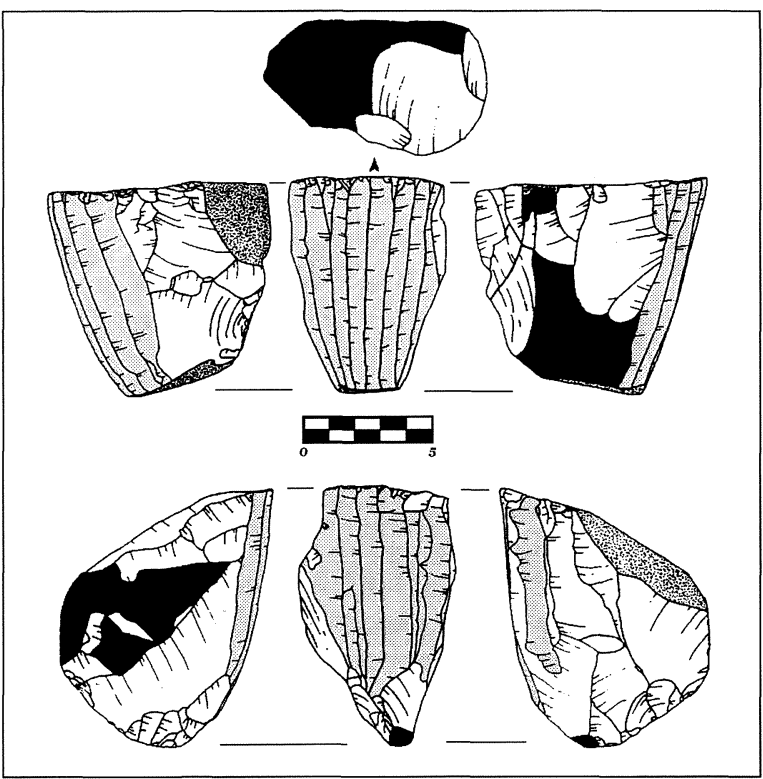

Fig. 3. Ejemplo de núcleos en plena fase de explotación para la producción de soportes laminares por presión (arriba, MF2-I-7; abajo, B6-256, ambos de Bòbila Madurell). La trama negra representa las zonas mates sin brillo o lustre térmico, la trama gris representa los frentes de explotación laminar.

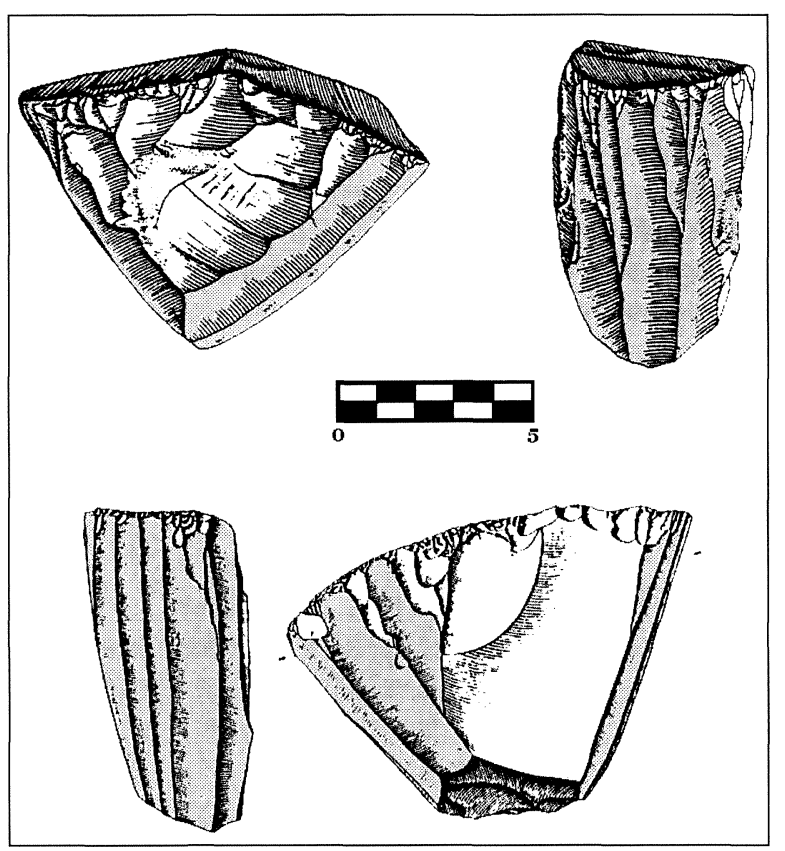

Fig. 4. Ejemplo de núcleos para la producción de soportes laminares por presión con dos frentes de explotación opuestos (arriba, núcleo procedente del sepulcro de Bòbila Negrell -Caldes de Montbui, Barcelona-, Ripoll y Llongueras, 1963; abajo, núcleo 14 de la sepultura G10 de Bòbila Madurell, dibujo J. Ariza). 
Dentro del proceso de configuración de los bloques de materia prima en núcleos o morfologías aptas para la producción de soportes laminares hemos diferenciado cuatro secuencias que incluyen varios procedimientos técnicos.

\section{a) El decorticado de los bloques de materia prima}

El escaso número de productos con restos de córtex y la ausencia de aquellos residuos generados durante el procedimiento de decorticación demuestran que el decorticado de los bloques de materia prima se realizó siempre fuera de los asentamientos estudiados. Desafortunadamente, desconocemos dónde se llevaba a cabo el decorticado y la preparación de los núcleos en morfologías aptas para la producción de soportes laminares mediante la presión: ¿en las propias zonas de aprovisionamiento?, ¿en otros asentamientos más próximos a las fuentes de materia prima?, ¿en lugares aún no hallados de los asentamientos excavados?

Básicamente, los únicos productos que conservan restos de la superficie cortical de los bloques de materia prima son los núcleos. La presencia en estos núcleos de una mayor o menor porción de la superficie cortical original no está en absoluto relacionada con un estado incipiente o avanzado de su configuración y/o explotación. Más bien, puede vincularse a un ajuste de las características morfológicas del bloque de materia prima a la abstracción volumétrica característica de esta sistemática de talla, ubicando en la misma sus elementos técnicos interactuantes, de tal manera que los restos de la superficie cortical original restan situados en los flancos, dorso y/o fondo del núcleo (Fig. 3) (10). De este modo, la decorticación de la base natural se confunde con la propia configuración del núcleo, sin que llegue a constituir un paso previo dentro de la misma.

Aún sin disponer de argumentos inequívocos que lo sustenten creemos que este procedimiento pudo ser llevado a cabo mediante el empleo de un percutor duro, al menos hasta la consecución del esbozo en el que posteriormente se ubican los elementos estructurales del núcleo.

(10) Consecuentemente, pueden localizarse lascas o lascas laminares con diverso grado de corticalidad como resultado del mantenimiento de la operatividad de estas zonas.

\section{b) La preparación inicial de los núcleos}

Su objetivo consiste en ubicar y/o crear el plano de presión y la/s superficie/s de lascado a partir del esbozo obtenido con anterioridad, así como establecer en el mismo el/los frentes de explotación del núcleo.

Los productos característicos de estas operaciones (lascas gruesas extraídas en la reducción del esbozo inicial del núcleo, lascas finas y alargadas extraídas con percutor blando para la preparación de la cresta y el adelgazamiento de los flancos, láminas en cresta, láminas de sección triangular y otros productos pseudolaminares, etc.) no están muy bien representados en los yacimientos estudiados y, en ocasiones, han sido formalizados mediante el retoque en otras morfologías.

En primer lugar, se procede al emplazamiento del plano de presión a partir de una superficie fracturada o de una gran extracción. Este plano constituye el punto de partida (plano de percusión) de las extracciones que tendrán como objetivo la preparación de las superficies de lascado principal/es y complementaria/s. Es muy posible que los planos de presión creados mediante extracciones centrípetas correspondan a reparaciones del plano de presión original, al haber podido resultar dañado durante su uso como plano de percusión en la preparación de las distintas superficies de lascado.

En la preparación de la/s superficie/s de lascado principal/es se crea en primer lugar una cresta cuya extracción, mediante la técnica de la presión, será utilizada para conformar la superficie de lascado principal a partir de la extracción, también por presión, de unos productos laminares preliminares de sección triangular.

Para la creación de la/s superficie/s de lascado secundaria/s se procede a adelgazar progresivamente los flancos con un percutor blando. Aunque este procedimiento se realice normalmente desde el plano de percusión (explotación unipolar), en ocasiones puede complementarse con extracciones realizadas desde una cresta ubicada en el fondo del núcleo mediante una transformación bifacial (Fig. 2).

\section{c) El tratamiento térmico (11)}

Los distintos tipos de alteración, tanto a nivel estructural como a nivel superficial, producidos

(11) Las afirmaciones más extendidas sobre las ventajas que ofrece el tratamiento térmico en la configuración, explotación y formalización de bloques, núcleos y soportes son las siguientes:

T. P., 59, n. ${ }^{\circ} 1,2002$ 
como consecuencia de la aplicación de este procedimiento técnico, así como los criterios que permiten su reconocimiento han sido definidos con detalle en un trabajo anterior (Terradas y Gibaja, 2001). Entre estos criterios, no hemos considerado el cambio de coloración original del sílex hacia tonalidades rojizas como un elemento definitivo puesto que su distribución e intensidad parecen variar en función de la representación cuantitativa de las partículas férreas de la roca silícea en cuestión (12) y de la temperatura alcanzada, siendo la duración de la exposición a la fuente calórica un factor secundario.

En cambio, la presencia del característico brillo o lustre térmico ha sido un elemento altamente diagnóstico. Esta alteración es identificable a partir de los negativos de las extracciones practicadas sobre el bloque, núcleo o soporte con posterioridad al tratamiento térmico (Fig. 3). Las superficies de dichos negativos aparecen netamente más lisas y brillantes, con aspecto grasiento, y contrastan claramente con el aspecto mate del resto de la morfología tratada. Al mismo tiempo, las ondulaciones debidas a la propagación de las ondas de choque a partir del punto de impacto quedan mejor impresas y de modo más regular, rasgos característicos de la homogeneidad de la materia en cuestión.

Una primera ordenación de los negativos de las extracciones según la presencia/ausencia de brillo o lustre térmico, conjuntamente con el análisis detallado de su disposición, dirección y del orden secuencial de su extracción, demuestra que dicho tratamiento térmico se aplicó sobre aquellos núcleos que ya habían sufrido una configuración previa, acorde a las normas descritas anteriormente.

A partir del registro arqueológico disponible hasta el momento para el nordeste peninsular, desconocemos la presencia de restos de sílex melado

- se reduce la fuerza necesaria a aplicar en la obtención de productos (Crabtree y Butler, 1964; Perlès, 1977; Rick, 1978; Bleed y Meier, 1980; Rick y Chappell, 1983; Joyce, 1985; Bertouille, 1989; Binder et al., 1990; Dunnell et al. 1994).

- se constata un mayor control en los procesos de configuración, explotación y formalización de bloques, núcleos y soportes, especialmente en aquellos dirigidos a la obtención de productos laminares, que permite una producción más estandarizada y de mejor calidad (filos con ángulos más agudos, disminución de la cantidad de bordes reflejados, etc.), (Rick, 1978; Purdy y Clark, 1979; Rick y Chappell, 1983; Bertouille, 1989; Dunnell et al., 1994).

- es posible obtener productos de mayor longitud (Rick, 1978; Bleed y Meier, 1980; Rick y Chappell, 1983).

(12) En el caso del sílex melado dicha coloración viene motivada por la presencia de hidróxidos férricos, normalmente limonita ortorómbica $2\left(\mathrm{Fe}_{2} \mathrm{O}_{3}\right)+3\left(\mathrm{H}_{2} \mathrm{O}\right)$ que, a partir de $\operatorname{los} 300^{\circ} \mathrm{C}$ de temperatura, se transforma en hematita romboédrica $\left(\mathrm{Fe}_{2} \mathrm{O}_{3}\right)$, variedad de oligisto de color rojo (Bertouille 1989). que atestigüen la existencia de accidentes durante este proceso, ya sea por sobreexposición térmica u horaria, cambios bruscos de temperatura, o cualquier otra causa. Suponemos que dichos accidentes, inherentes al riesgo que comporta la aplicación de un tratamiento térmico sobre un bloque, núcleo o soporte de roca silícea, debieron de ser frecuentes. De todos modos, su ausencia debe estar relacionada con la falta de documentación de dicha práctica en los contextos arqueológicos estudiados.

En otros puntos de la Península ibérica también se referencia el empleo del tratamiento térmico a partir del Neolítico antiguo y medio (mediados del VI milenio $\mathrm{BC}$ a finales del III milenio BC, según fechas no calibradas). Así, en Portugal se documenta en la gruta do Almonda en Torres Novas -Santarém- (Zilhão y Carvalho, 1996), y en España en la cueva del Toro en Antequera -Málaga- (Rodríguez et al., 1996), y en el asentamiento de Castillejos en Montefrío-Granada-(Martínez et al., 1998). No obstante, es en el Mediterráneo occidental, y más concretamente en el área adscrita cronológica y culturalmente al Chasséen francés, donde se ha constatado una gran proliferación en el uso de este recurso técnico para la explotación de bloques de sílex melado de buena calidad. Una buena prueba de ello lo constituyen, por ejemplo, los materiales de los yacimientos franceses de Acourt (Mormoiron, Vaucluse), Baume Fontbrégoua (Salernes, Var), L'Eglise (Baudinard, Var), Fanaud (Entrechaud, Vaucluse), Trets-Sainte-Catherine (Bouches-du-Rhône), La Cabre (Saint Raphaël, Var), etc. (Masson, 1984; Binder, 1984; 1991; Binder y Gassin, 1988; Binder et al., 1990; Gassin, 1993; 1996; Lea, 1997).

\section{d) La configuración definitiva de los núcleos}

Con posterioridad al calentamiento al que son sometidos los núcleos ya configurados, se realizan una serie de extracciones que tienen como objetivo finalizar la conformación de los núcleos. No se trata de una fase distinta a la que hemos visto anteriormente en cuanto a los objetivos que la dirigen, sino en cuanto al momento en el que se lleva a cabo esta operación.

El bajo número de extracciones que se realizan en este momento, fácilmente identificables a partir del brillo térmico presente en sus negativos, así como su escasa trascendencia en la conformación del núcleo, parecen atestiguar una finalización de 
la fase de configuración con el objetivo de reparar pequeños detalles, deficiencias o accidentes acrecentados mediante el tratamiento térmico. Es en este momento, cuando se ha materializado definitivamente la concepción volumétrica representativa de la producción de soportes laminares por presión (Fig. 2).

\subsection{La explotación de los núcleos}

Esta etapa se inicia a partir de la explotación de las morfologías configuradas previamente con el objetivo de obtener una serie de productos laminares estandarizados (Fig. 3).

El primer paso corresponde a la regularización de la superficie de lascado creada anteriormente. Esto se lleva a cabo mediante la extracción de las primeras láminas, todavía de sección triangular, hasta conseguir soportes suficientemente regulares como para que, con una correcta elección del emplazamiento de la siguiente extracción, se desarrolle un orden sistemático en los levantamientos propicio para la producción de láminas de sección trapezoidal (Fig. 2). Este orden se verá interrumpido ocasionalmente por la extracción de láminas sobrepasadas lateralmente, de perfil más irregular, correspondientes a las zonas marginales de la superficie de lascado.

Las extracciones se realizan mediante la presión ejercida con un instrumento presionador. Desconocemos la naturaleza de este instrumento, si bien a partir de los trabajos experimentales publicados (Pelegrin, 1984c; 1988; Texier, 1982; 1983; 1984; Inizan et al., 1995), y en función de la longitud de los productos obtenidos, creemos que debería tratarse de una muleta pectoral o abdominal, cuya punta sería confeccionada con una materia dura de origen animal (asta, hueso).

Normalmente, la explotación del núcleo se desarrolla a partir de una única superficie de lascado ubicada en el plano de simetría transversal. Sólo en unas pocas ocasiones hemos podido constatar la presencia de dos superficies de lascado opuestas (Fig. 4), situadas en ambos planos de simetría transversal (Fig. 2). La relación entre dichos frentes de explotación no es de complementariedad, sino que parecen haberse implementado con la posibilidad de llevar a cabo dos explotaciones sucesivas. Hasta el presente, este tipo de explotación laminar no se ha observado en contextos atribuibles al Chasséen francés (comunicación personal $\mathrm{F}$. Briois).
En este tipo de explotación laminar es imprescindible la correcta preparación del punto sobre el que se va a ejercer la presión. Este acondicionamiento consiste en eliminar constantemente las cornisas que con cada extracción se han ido generando, ya sea mediante la realización de pequeñas extracciones o bien, en alguna ocasión, mediante su abrasión.

Si bien la dinámica de explotación de estos núcleos tiende a mantener la concepción volumétrica que dirige esta sistemática de talla, pueden llevarse a cabo operaciones concretas, de poca intensidad, destinadas a la reparación o reconfiguración de los distintos elementos estructurales de la morfología explotada con el objetivo de mantener su operatividad (Fig. 2):

- plano de presión: mediante pequeñas extracciones centrípetas con el objetivo de reparar el frente de explotación del núcleo, comportando una disminución de la longitud de las superficies de lascado y, consecuentemente, de los productos laminareś obtenidos.

- superficie/s de lascado principal/es: a partir de un cambio en el orden de extracción de láminas con la finalidad de reparar posibles errores (láminas reflejadas, secciones no trapezoidales, etc.) y mantener la convexidad longitudinal de la superficie de lascado, significando una disminución mínima del volumen de materia prima explotable y, por tanto, del número de productos que se podrían obtener.

- superficie/s de lascado secundaria/s: mediante extracciones para mantener la amplitud del frente de explotación y la convexidad de la carena transversal de la superficie de lascado.

Los núcleos recuperados en los contextos arqueológicos estudiados fueron abandonados en plena fase de explotación (Figs. 3 y 4), en el momento de su máxima productividad, por lo que no es fácil observar situaciones en las que se haya perdido la operatividad de su concepción volumétrica (13).

\subsection{La formalización de los soportes laminares}

El objetivo que dirige la explotación de los núcleos mediante la técnica de la presión según la dinámica expuesta es la producción seriada y estan-

(13) La presencia de un cierto número de núcleos de tamaño menor parece estar más relacionada con las dimensiones originales del bloque de materia prima que con una intensificación de la producción (núcleos en estado avanzado de explotación, reaprovechados, etc.)

T. P., 59, n. ${ }^{\circ} 1,2002$ 


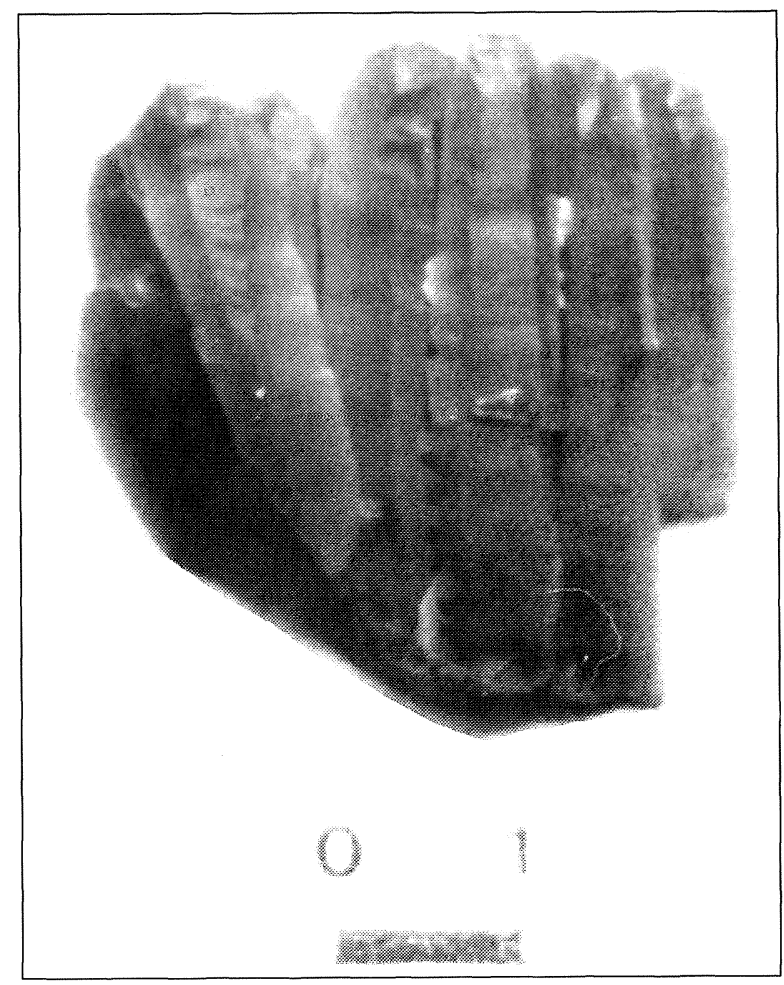

Fig. 5. Remontaje de láminas sin usar recuperadas en la sepultura B6 de Bòbila Madurell.

darizada de soportes laminares. Las características morfotécnicas de estos productos laminares no difieren de las especificadas anteriormente (cf. supra): láminas finas y estrechas, con bordes y aristas regularmente paralelos, sección trapezoidal y morfología triangular característica de los núcleos con una concepción volumétrica cónica (Fig. 5).

A partir del análisis de las huellas de uso preservadas en las aristas y superficies de los instrumentos (Clemente y Gibaja, 1998; Gibaja, 1997; en prensa; Gibaja y Clemente, 1996; Gibaja et al., 1997), hemos observado que este tipo de producción laminar permitió la consecución de unos soportes idóneos y efectivos, fácilmente enmangables, con los que poder transformar distintas materias de origen animal, vegetal y/o mineral. A su vez, dichos soportes pudieron ser transportados fácilmente y en gran cantidad para su utilización o formalización en otros contextos, y/o intercambio con otros grupos humanos.

Otra opción fue la de formalizar algunos de los productos laminares obtenidos a lo largo de estos procesos mediante una modificación premeditada de su morfología, ya sea con el objetivo de:
- obtener un mayor ajuste de su morfología a la función a realizar,

- modificar su morfología para mejorar su prensión o su ajuste a un enmangue o a un astil,

- mantener su operatividad como instrumento.

El tipo de formalización mayormente documentado es la modificación de los bordes de los productos laminares, enteros o fragmentados, mediante el retoque por percusión. En ocasiones, este tipo de retoque fue practicado para llevar a cabo una modificación de las fracturas transversales de segmentos de lámina, originando morfologías trapezoidales (bitruncaduras) (Fig. 6). Ocasionalmente, el retoque por percusión también fue empleado para generar otros tipos de morfologías (denticulados, raspadores, perforadores), que apenas tienen representación en el registro arqueológico.

Una técnica distinta fue el empleo de la presión para modificar fragmentos de soportes laminares a partir de un retoque bifacial poco invasor, otorgándoles una morfología apuntada específica, con pedúnculo y aletas (Fig. 6). En ningún caso, se ha observado un tratamiento térmico previo de dichos soportes para llevar a cabo este tipo de formalización.

\subsection{La función de los productos $y$ subproductos laminares}

El análisis traceológico realizado sobre todos estos tipos de productos recuperados en yacimientos del Neolítico medio catalán (Clemente y Gibaja, 1998; Gibaja, 1997; en prensa; Gibaja y Clemente, 1996; Gibaja et al., 1997), nos ha permitido discernir qué productos líticos fueron empleados y en qué actividades productivas participaron, a partir de la reconstrucción de la cinemática del instrumento y de la identificación de la materia trabajada. De este modo, hemos podido disponer de un método de contrastación de los objetivos que han dirigido la producción lítica.

A partir de estos datos, hemos podido comprobar que estos productos fueron usados en una gran variedad de actividades: caza, descarnado de animales, tratamiento de las pieles en varios estadios de su preparación, siega de cereales, procesado de los tallos de dichos cereales, o elaboración de objetos en hueso, madera y materias minerales. Pero los instrumentos destinados a estas funciones no siempre tuvieron las mismas características morfológicas, puesto que variables como la dureza de la materia 

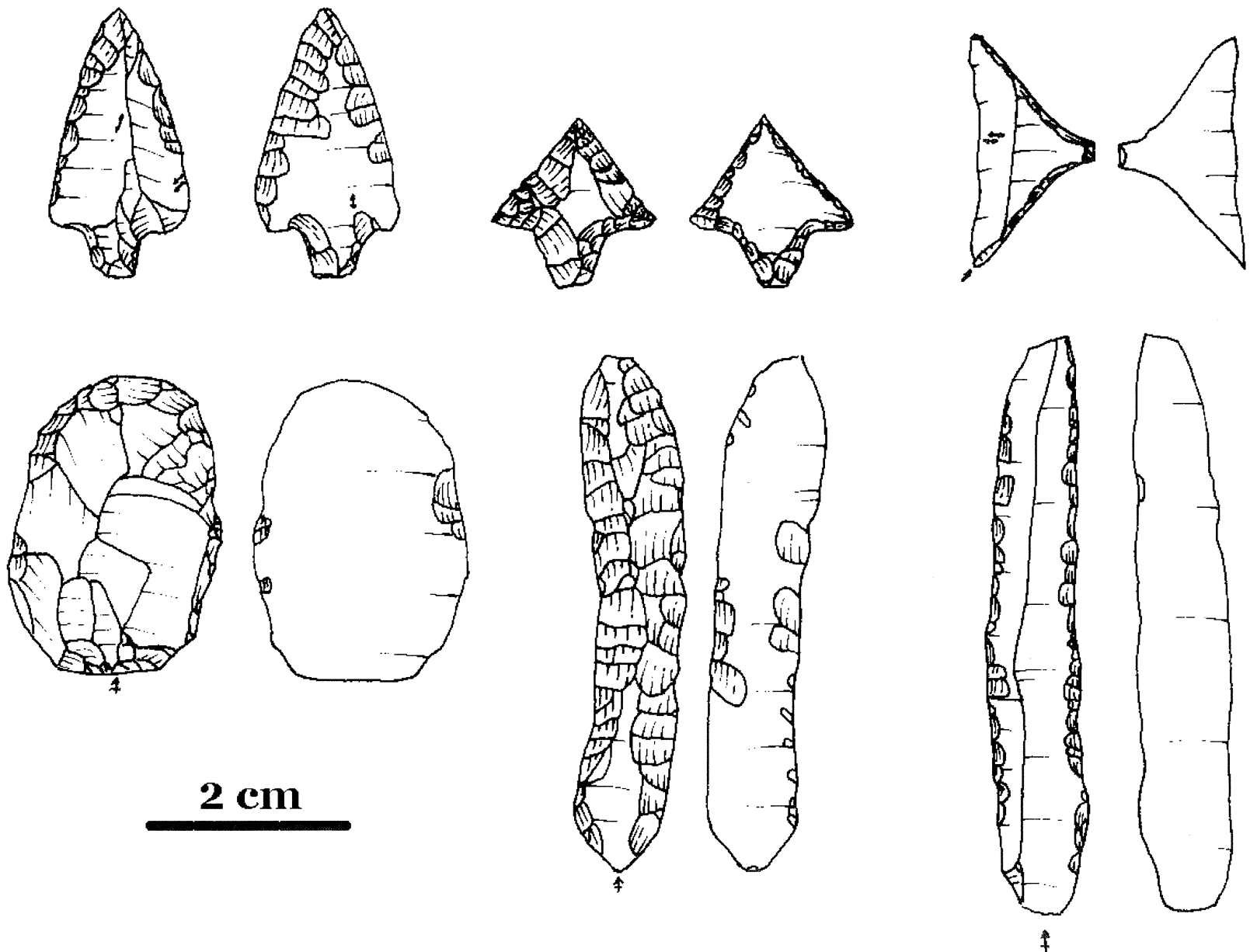

Fig. 6. Productos formatizados mediante retoque procedentes de distintas sepulturas de Bòbila Madurell.

trabajada o el movimiento efectuado influyeron determinantemente en las mismas. Así, cabe decir que:

- para el descarnado, corte de piel o siega se usaron especialmente láminas de filos largos y agudos $\left(10-30^{\circ}\right)$, en estado bruto, sin retocar;

- para el raspado de la piel seca, se emplearon lascas y láminas sin retocar y raspadores, todos ellos con un ángulo de filo en ocasiones muy obtuso $\left(40-90^{\circ}\right)$;

- para el raspado del hueso y la madera, lascas sin retocar o láminas con una pequeña escotadura. En este caso el ángulo de los filos también fue obtuso $\left(30-80^{\circ}\right)$;

- para las actividades cinegéticas se elaboraron proyectiles con puntas y/o bitruncaduras geométricas;

- para las tareas de perforación de las materias duras se emplearon perforadores realizados sobre lasca o lámina.
El análisis de materiales depositados en contextos funerarios nos ha permitido comprobar que parte de los restos líticos depositados como elementos de ajuar en las necrópolis de Bòbila Madurell y Camí de Can Grau, habían sido usados previamente para todo el abanico de trabajos apuntados anteriormente (14). Ello nos lleva a la conclusión de que productos que, en principio, habían tenido un carácter subsistencial y/o técnico, posteriormente adquirieron un carácter ideológico (Fig. 7). Es decir, que dejaron de formar parte de los instrumentos destinados a la subsistencia del grupo para contribuir a la reproducción social del mismo.

Pero no todos los productos depositados en las sepulturas tuvieron una función específica previa.

(14) En el caso de Bòbila Madurell, el $53 \%$ de los restos líticos analizados presentan evidencias inequívocas de su utilización previa. En el caso de Camí de Can Grau, este porcentaje se eleva al $78 \%$ de los restos analizados. 


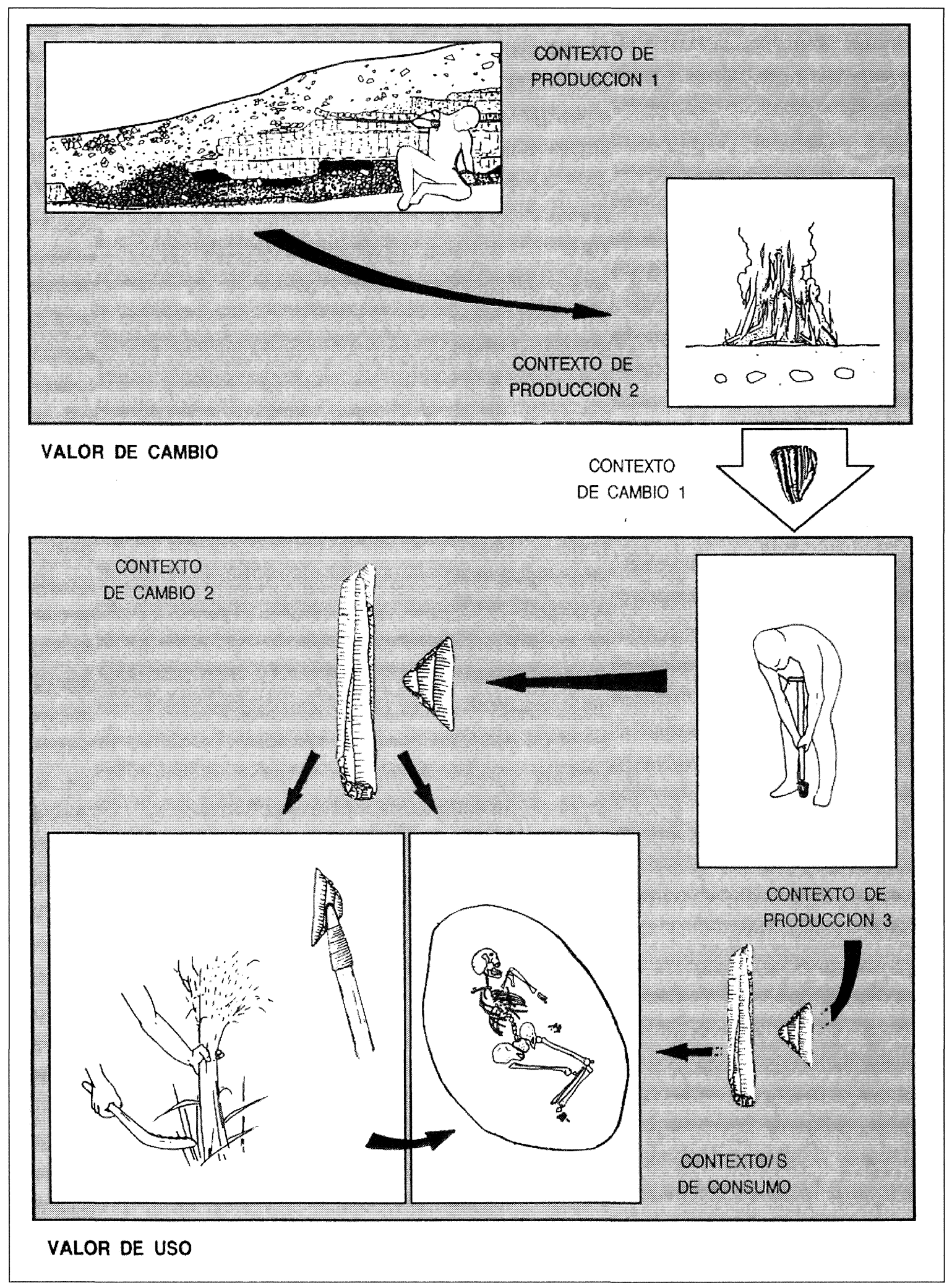

Fig. 7. Representación esquemática de la gestión social del sílex melado en el Neolítico medio del nordeste peninsular. 
La presencia en algunos sepulcros de Bòbila Madurell de láminas sin usar y que remontaban entre sí (Fig. 6) (15) es indicativa de que, en ciertas circunstancias, los objetivos que guiaron la producción lítica estuvieron exclusivamente relacionados con la consecución de productos para acompañar el cadáver inhumado (Fig. 7).

\section{RECONSTRUCCIÓN DE LA GESTIÓN SOCIAL DEL SÍLEX MELADO EN EL NEOLÍTICO MEDIO DEL NORDESTE PENINSULAR}

La caracterización de la producción de soportes laminares por presión sobre sílex melado y de su función permite reconstruir aquellas estrategias implementadas por los grupos humanos del nordeste peninsular en la gestión de este recurso mineral durante el Neolítico medio.

Para ello, hemos realizado una lectura interpretativa de dichas estrategias en función de su dinámica cronológica y geográfica, es decir, a partir del seguimiento de las distintas actividades productivas en las que interviene este tipo específico de materia prima, desde su contexto geológico original hasta el contexto o contextos arqueológicos en los que son recuperados productos de esta actividad social (Fig. 7). Esta lectura permite constatar el tipo de organización técnica de las actividades productivas involucradas a partir de la dinámica seguida por los distintos elementos del proceso productivo en los procesos de trabajo en los que intervienen (Terradas, 1996; 1998).

La determinación de la procedencia de las materias primas explotadas contribuye a delimitar el medio ambiente en el que opera la actividad social. En este sentido, el aprovisionamiento de sílex melado por parte de los grupos humanos del Neolítico medio en Catalunya presenta interrogantes sobre su origen geográfico y geológico, el tipo de aprovisionamiento realizado, o el modo de introducción de estas materias primas en los asentamientos (bloques brutos, núcleos, productos, etc.).

A partir de una procedencia supuestamente foránea (sudeste francés: Vaquer, 1990; Binder, 1998), el registro arqueológico recuperado en los yacimientos estudiados permite documentar una intro-

(15) Recientemente, hemos podido constatar personalmente otro remontaje de 3 láminas de sílex melado sin usar en una sepultura localizada en la mina 83 -Can Badosa- del complejo minero de Gavà (Barcelona). ducción del sílex melado bajo morfologías específicas (principalmente soportes laminares en estado bruto y segmentos de lámina formalizados mediante retoque y, en menor medida, núcleos) (16).

En función del papel desempeñado en el proceso productivo global de estos grupos humanos, dichos productos pueden ser considerados como materia prima (los núcleos, en tanto que se convierten en el objeto de trabajo sobre el que se desarrollará una futura explotación laminar), e instrumentos (las láminas y segmentos formalizados, al integrarse en posteriores actividades relacionadas con la reproducción biológica y social).

La introducción del sílex melado bajo dichas morfologías es una consecuencia de los procesos de transformación a los que los bloques de esta materia prima son sometidos, como mecanismo de ajuste a la naturaleza e intensidad del transporte al que se verán sujetos, dando lugar a formas tecnológicas de transporte (Geneste, 1992). Dicha medida puede integrarse a la ley general que presupone una tendencia en la producción lítica a minimizar el coste de producción de los instrumentos líticos (17) y a maximizar su rendimiento. Ambos conceptos conllevan implícita una planificación de la dinámica productiva, diseñada en función de las necesidades sociales que dirigen la producción lítica (Terradas, 1996; 1998).

De la consecución de estos bienes de consumo se derivaron una serie de residuos y productos desechados (restos corticales, lascas de preparación de la configuración del núcleo, láminas en cresta, sin que en ninguno de ellos aparezca brillo o lustre térmico), cuya escasa representación no permite constatar el desarrollo de determinadas fases de la producción lítica (configuración de los núcleos) en contextos arqueológicos del nordeste peninsular.

Los núcleos recuperados en los contextos arqueológicos estudiados se hallan en plena fase de explotación sin que, en absoluto, hayan agotado su capacidad productiva. Dichos núcleos presentan un

(16) A este respecto, la presencia de un tipo de alteración microscópica particular observada en las superficies de los núcleos -pulido G- (Moss, 1983), puede ser indicativa de un frotamiento o roce entre distintos productos líticos. Su presencia exclusiva en las zonas mates de los núcleos, sin brillo o lustre térmico, podría ser atribuible al transporte y/o almacenado de estos núcleos junto a otros núcleos, bloques de materia prima, percutores, abrasionadores, etc. (Moss, 1983; Cahen y Caspar, 1984; Plisson, 1987; comunicación personal E. I. Guiria).

(17) En el caso del instrumental lítico dicho coste constituye una estimación relativa, en términos de tiempo y energía invertidos, del coste que representa el aprovisionamiento de una materia prima y su posterior transformación en instrumentos para un grupo humano (Perlès, 1992; Terradas, 1996). 
tratamiento térmico previo, realizado durante la fase de configuración (cf. supra) que, probablemente, tendría lugar cerca de las zonas de aprovisionamiento del sílex melado al no documentarse evidencias del mismo en los contextos del nordeste peninsular (accidentes relacionados con cambios bruscos de temperatura o con una sobreexposición calórica u horaria, etc.) (18).

La implementación de esta particular forma tecnológica de transporte (núcleos configurados y tratados térmicamente), coincide con la finalización de la fase a la que se confiere la máxima importancia dentro del desarrollo de la sistemática de talla basada en la producción de soportes laminares por presión. Tanto es así que se tiende a asociar el logro de la regularidad volumétrica del núcleo configurado, indispensable para su óptima explotación y rendimiento, con la presencia de personas y talleres especializados en la explotación del sílex melado (Courtin, 1974; Pelegrin, 1984c; Binder et al., 1990).

En este sentido, la preparación tan metódica de los núcleos no sólo habría constituido una obligación técnica indispensable para obtener una serie estandarizada de productos laminares y sacar el máximo provecho de una materia prima preciada, sino que también habría facilitado su explotación futura por otros grupos humanos (Binder et al., 1990; Gassin, 1996; Lea, 1997; Binder, 1998). Ello es posible debido a que la dinámica de explotación de estos núcleos comporta menos situaciones constrictivas que su configuración, lo cual facilitaría la producción de soportes laminares por parte de terceras personas con un menor grado de especialización en dicha sistemática de talla (19).

Partiendo de la base que la producción de los bienes materiales puede ser jerarquizada mediante la aplicación de un criterio de valoración social (Terradas, 1996), el valor que se otorgue a un bien de consumo vendrá condicionado por su capacidad resolutiva frente a distintas necesidades sociales, de

(18) Otro elemento que permite sustentar esta hipótesis es el riesgo elevado de accidentes, que desaconseja el tratamiento térmico de los bloques o núcleos de sílex melado en contextos alejados de sus zonas de aprovisionamiento, puesto que su eventual reemplazo comportaría un coste de producción superior.

(19) Es posible que el tratamiento térmico no resultara un procedimiento técnico imprescindible a tenor de la excelente aptitud que presenta el sílex melado para la producción de soportes laminares por presión (Pelegrin, 1988). Por ello, algunos autores (Lea, 1997) sugieren que el calentamiento de estos núcleos podría constituir una operación destinada a facilitar la explotación de núcleos bien conformados por parte de personas menos capaces. acuerdo a la función que éste ejerza dentro del conjunto de la reproducción biológica y social de la sociedad.

De este modo, la finalidad de la producción de estos núcleos configurados iría dirigida hacia el intercambio, es decir, hacia la producción de valores de cambio, sin excluir que una parte de la producción fuera destinada al consumo propio (valores de uso), inmediato o diferido. No obstante, para el grupo social receptor de estos núcleos, los mismos no dejarían de constituir bienes de consumo con un valor de uso (Fig. 7).

Existe la posibilidad que en la configuración de los núcleos existiese un sesgo espacio-temporal, en base a las operaciones realizadas con anterioridad o posterioridad a la aplicación del tratamiento térmico, originando sendos contextos de producción (20) (Fig. 7). Así, mientras el decorticado de los bloques de materia prima y la preparación inicial de los núcleos podría llevarse a cabo en las propias zonas de aprovisionamiento de materia prima (lo que permitiría reducir su volumen y peso y, por tanto, el coste energético relativo a su transporte), el cuidadoso tratamiento térmico de los núcleos y la configuración definitiva de los mismos pudo realizarse en los asentamientos de los grupos que llevaron a cabo la explotación de este recurso mineral.

Si bien, a tenor del registro arqueológico de algunos de los contextos arqueológicos del Neolítico medio del nordeste peninsular, el sílex melado sería introducido bajo la morfología de soportes laminares en estado bruto y segmentos de lámina formalizados mediante retoque, en otros (Bòbila Madurell) se constata la introducción de dicha materia prima como núcleos conformados.

Esta circunstancia evidencia la existencia (en Bòbila Madurell u otros asentamientos arqueológicos), de un desarrollo de la fase de explotación de los núcleos en el propio contexto de consumo, con el objetivo de producir valores de uso de naturaleza mineral, al mismo tiempo que una redistribución de dichos productos laminares hacia otros contextos de consumo (producción de valores de cambio) (Fig. 7).

Tal como hemos visto anteriormente, los usos a los que son destinados los distintos instrumentos

(20) Por ejemplo, yacimientos como Veaux-Malaucène con una estratigrafía superior a los 6 metros de espesor en la que se documenta una gran proporción de residuos y desechos de sílex melado, o la grotte du Levant de Leaunier y el abri Grangeon, donde también se han registrado numerosos desperdicios de talla (Beeching, 1991; Binder, 1991; 1998). 
líticos obtenidos a lo largo de esta secuencia productiva son dispares, pudiendo adquirir un carácter subsistencial, técnico y/o ideológico (Fig. 7), ya sea de forma exclusiva o sucesiva, de acuerdo a la función que ejerzan dentro del conjunto de la reproducción biológica y social de la sociedad.

La reconstrucción que aquí hemos presentado de la gestión del sílex melado por parte de las sociedades del Neolítico medio del nordeste peninsular no constituye más que un esbozo, realizado en función de los resultados disponibles hasta el momento, de las estrategias implementadas por estas sociedades en la gestión de un recurso mineral concreto. $\mathrm{Al}$ mismo tiempo, pretendemos romper la tendencia que ha caracterizado este tipo de estudios en nuestro país, fundamentada en aspectos tipológicos y descriptivos, enfatizando en aspectos sociales de la producción lítica. De todos modos, cabe recordar que el sílex melado sólo representa uno de los recursos minerales explotados por estas sociedades, si bien quizás sea al que tradicionalmente se le ha concedido más importancia y trascendencia.

Dichas estrategias deben confrontarse, en un marco de estudio más amplio y de carácter interdisciplinar e interfronterizo, con las desarrolladas en la explotación de otros recursos minerales en primer lugar, y del resto de recursos naturales en segunda instancia, puesto que la explicación del tipo de gestión llevada a cabo con los recursos minerales, así como de su causalidad y singularidad, no puede ser desvinculada de la explicación del resto de procesos productivos de la sociedad.

\section{BIBLIOGRAFÍA}

AA.VV. (1982): El Neolític a Catalunya (Taula rodona de Montserrat). Publicacions de l'Abadia de Montserrat. Montserrat (Barcelona).

AA.VV. (1992): Estat de la investigació sobre el Neolític a Catalunya (9è Col-loqui Internacional d'Arqueologia de Puigcerdà). Puigcerdà (Girona).

AA.VV. (1996): I Congrés del Neolític a la Península ibèrica (Gavà-Bellaterra 1995). Rubricatum 1.

BEECHING, A. (1991): "Sépultures, territoire et société dans le Chasséen Méridional: l'exemple du Bassin Rhodanien”. En A. Beeching, D. Binder, J.C. Blanchet, C. Constantin, J. Dubouloz, R. Martínez, D. Mordant, J.P. Thevenot y J. Vaquer (dirs.): Identité du Chasséen (Actes du colloque international de Nemours, 1989). Memoires du Musée de Préhistoire d'Ile de France 4: 327 341. Nemours.
Bernabeu, J. y Orozco, T. (eds.) (1999): II Congrés del Neolític a la Península ibèrica (València 1999). Saguntum. Papeles del Laboratorio de Arqueología de Valencia extra-2. València.

Bertouille, H. (1989): Théories physiques et mathématiques de la taille des outils préhistoriques. Cahiers du Quaternaire, 15. Éditions du CNRS. Paris.

Binder, D. (1984): "Systèmes de débitage laminaire par pression: exemples chasséens provençaux". En AA.VV.: Économie du débitage laminaire. Préhistoire de la pierre taillée 2. Cercle de recherches et d'études préhistoriques. Meudon: 71-84.

- (1991): "Facteurs de variabilité des outillages lithiques chasséens dans le sud-est de la France". En A. Beeching, D. Binder, J.C. Blanchet, C. Constantin, J. Dubouloz, R. Martínez, D. Mordant, J.P. Thevenot y J. Vaquer (dirs.): Identité du Chasséen (Actes du colloque international de Nemours, 1989). Mémoires du Musée de Préhistoire d'Ile de France 4: 261-272. Nemours.

- (1998): "Silex blond et complexité des assemblages lithiques dans le Néolithique liguro-provençal". En A. d'Anna y D. Binder (dirs.): Production et identité culturelle. Actualité de la recherche. Éditions APDCA. Antibes: 111-128.

Binder, D. y Gassin, B. (1988): "Le débitage laminaire chasséen après chauffe: technologie et traces d'utilisation". En S. Beyries (ed.): Industries lithiques: tracéologie et technologie. Volume 1: aspects archéologiques. BAR International Series 411 (I). Hadrian Books Ltd. Oxford: 93-125.

Binder, D.; Perlès, C.; Inizan, M.L. y Lechevallier, M. (1990): "Stratégies de gestion des outillages lithiques au Néolithique". Paléo 2: 257-283.

BleEd, P. y Meier, M. (1980): "An objective test of the effects of heat treatment of flakeable stone". American Antiquity 45 (3): 502-507.

Bosch Gimpera, P. (1919): "Prehistoria catalana". Enciclopedia catalana, XVI. Barcelona: 86-99.

Bosch, J. (1995): "El món funerari al Neolític i al Calcolític al curs inferior de l'Ebre". L'arqueologia de la mort: el món funerari a l'antiguitat a la Catalunya Meridional. Citerior, 1: 15-31, Tarragona.

Bosch, J. y Estrada, A. (1998): "L'estudi de la mineria neolítica a Gavà en el seu context ambiental i socioeconòmic". En J. Bosch; X. Terradas y T. Orozco (eds.): Actes de la 2 a reunió de treball sobre aprovisionament de recursos lítics a la Prehistòria. Rubricatum, 2: 129-136.

Bosch, J.; Estrada, A. y Noain, M.J. (1996): "Minería neolítica en Gavà (Baix Llobregat, Barcelona)". Trabajos de Prehistoria 53 (1): 59-71.

Boujot, C.; Crubézy, E. y Duday, H. (1991): “L'Identité du Chasséen à travers des structures et pratiques funéraires”. En A. Beeching, D. Binder, J.C. Blanchet, C. Constantin, J. Dubouloz, R. Martínez, D. Mordant, J.P. Thevenot y J. Vaquer (dirs.): Identité du Chasséen (Ac-

T. P., 59, n. ${ }^{\circ} 1,2002$ 
tes du colloque international de Nemours, 1989). Mémoires du Musée de Préhistoire d'Ile de France 4: 413420. Nemours.

Briois, F.; Claustre, F.; Dones, C. y Dones, S. (1990): "Industrie Chasséenne et circulation des matières premières en Roussillon: l'exemple de Villelongue-delsMonts". Travaux de préhistoire catalane 6: 123-127.

CAHEN, D. y CASPAR, J.P. (1984): "Les traces d'utilisation des outils préhistoriques”. L'Anthropologie 88: 277-308.

Clemente, I. y GibajA, J.F. (1998): "Working processes on cereals: an approach through microwear analysis". Journal of Archaeological Science 25 (5): 457-464.

Courtin, J. (1974): Le Néolithique de la Provence. Mémoire de la Société Préhistorique Française 11. Paris.

CrabtreE, D.E. (1968): "Mesoamerican polyhedral cores and prismatic blades". American Antiquity 33 (4): 446478.

Crabtree, D.E. y Butler, R. (1964): "Notes on experiments in flintknapping. 1: heat treatment of silica materials". Tebiwa 7 (1): 1-6.

CurA, M. (1975): "Consideraciones sobre los enterramientos en cista neolíticas y su evolución posterior en Catalunya". Actas del XIII Congreso Nacional de Arqueología (Huelva 1973): 279-288. Zaragoza.

- (1976): "El grup cultural de les cistes neolítiques del pre-Pirineu català (el Solsonià)". Cypsela 1: 49-52.

Dunnell, R.C.; McCutcheon, P.T.; IKeya, M. y Toyoda, S. (1994): "Heat treatment of mill creck and dover cherts on the Malden Plain, Southeast Missouri". Journal of Archaeological Science 21: 79-89.

Gassin, B. (1993): Approche fonctionnelle des industries lithiques du Néolithique provençal. L'exemple du site chasséen de la grotte de l'Eglise supérieure. Thèse de doctorat. Université de Paris-X. Nanterre.

- (1996): Evolution socio-économique dans le Chasséen de la grotte de l'Eglise supérieure (Var): Apport de l'analyse fonctionelle des industries lithiques. Monographie du Centre de Recherches Archéologiques 17. Éditions du CNRS. Paris.

GeNESTE, J.M. (1992): "L'approvisionnement en matières premières dans les systèmes de production lithique: la dimension spatiale de la technologie". En R. Mora, X. Terradas, A. Parpal y C. Plana (eds.): Tecnología y cadenas operativas líticas. Treballs d'Arqueologia 1. Universitat Autònoma de Barcelona: 1-36.

GibajA, J.F. (1997): “Anàlisi funcional del material lític de la necròpoli del Camí de Can Grau”. En M. Martí, R. Pou y X. Carlús: Excavacions arqueològiques a la ronda sud de Granollers (1994): La necròpoli del Neolític mitjà i les restes romanes del Camí de Can Grau (la Roca del Vallès, Vallès Oriental) i els jaciments de Cal Jardiner (Granollers, Vallès Oriental). Excavacions arqueològiques a Catalunya 14. Generalitat de Catalunya. Barcelona: 128-141.

- (e.p.): "Ca N'Isach (Palau Sabardera, Girona, Pirineos Orientales): estrategias económicas y procesos de tra- bajo inferidos a partir del análisis funcional del material lítico". En J. Maroto (ed.): II Congreso Internacional de Historia de los Pirineos (Girona, 11-14 Noviembre 1998). Universidad Nacional de Educación a Distancia. Girona.

Gibaja, J.F. y Clemente, I. (1996): “Análisis funcional del material lítico de las sepulturas de la Bòbila Madurell (Sant Quirze del Vallès, Barcelona)". En AA.VV.: I Congrés del Neolític a la Península ibèrica (Gavà-Bellaterra 1995). Rubricatum, 1 (I): 183-189.

Gibaja, J.F.; Clemente, I. y Vila, A. (1997): "Una aproximación a través del análisis funcional a las sociedades neolíticas del Nordeste peninsular: las necrópolis de la Bòbila Madurell y el Camí de Can Grau”. En R. de Balbín y P. Bueno (eds.): II Congreso de Arqueología peninsular II: Neolítico, Calcolítico y Bronce. Fundación rei Afonso Henriques. Zamora: 129-136.

Granados, O.; Puig, F. y Farré, R. (1993): “La intervenció arqueològica a Sant Pau del Camp: un nou jaciment prehistòric al Pla de Barcelona". Tribuna d'Arqueologia 1991-1992: 27-38.

INIZAN, M.L. (1991): "Le débitage par pression: des choix culturels". En AA.VV.: 25 ans d'études technologiques en Préhistoire. Bilan et perspectives. Éditions APDCA. Juan-les-Pins: 367-377.

InIZAN, M.L.; REduron, M.; Roche, H. y TiXIER, J. (1995): Technologie de la pierre taillée. Préhistoire de la pierre taillée 4. Cercle de recherches et d'études préhistoriques. Meudon.

JoYCE, D.J. (1985): "Heat treatment of alibates chalcedony". Lithic Technology 14 (1): 36-40.

LEA, V. (1997): Contribution à l'étude des sites chasséens de plein air: étude technologique de l'industrie en silex blonds su site de la Cabre (Var). Mémoire en vue de l'obtention de la maitrise. Université de Provence. Aixen-Provence.

Llongueras, M.; Marcet, R. y Petit, M.A. (1986): “La cultura catalana de los sepulcros de fosa y su relación con el chasseense". En J.P. Demoule y J. Guilaine (dirs.): Le Néolithique de la France. Picard. Paris: 251-258.

Martí, M.; Poy, R. y CARLús, X. (1997): Excavacions arqueològiques a la ronda sud de Granollers (1994): La necròpoli del Neolític mitjà $i$ les restes romanes del Camí de Can Grau (la Roca del Vallès, Vallès Oriental) i els jaciments de Cal Jardiner (Granollers, Vallès Oriental). Excavacions arqueològiques a Catalunya 14. Generalitat de Catalunya. Barcelona.

Martín, A. (1986-1989): "Reflexión sobre el estado de la investigación del Neolítico en Catalunya y su reflejo en la cronología radiométrica". Empúries 48-50 (II): 84102.

- (1992): "El Neolític mitjà ple: nova estratègia d'organització social i econòmica". En AA.VV.: Estat de la investigació sobre el Neolític a Catalunya (9è Col-loqui Internacional d'Arqueologia de Puigcerdà): 164-166. Puigcerdà (Girona). 
Martín, A. y TARrús, J. (1991): “Les groupes de l'horizon néolithique moyen catalan et ses rapports avec le Chasséen". En A. Beeching, D. Binder, J.C. Blanchet, C. Constantin, J. Dubouloz, R. Martínez, D. Mordant, J.P. Thevenot y J. Vaquer (dirs.): Identité du Chasséen (Actes $d u$ colloque international de Nemours, 1989). Memoires du Musée de Préhistoire d'Ile de France 4: 81 90. Nemours.

- (1995): "Neolític i megalitisme a la Catalunya sudpirinenca". En AA.VV.: Cultures i medi. De la prehistòria a l'edat mitjana (Homenatge al professor Jean Guilaine). Institut d'Estudis Ceretans. Puigcerdà (Girona): 241-260.

Martínez, G.; Morgado, A.; Afonso, J. A.; Sánchez, M. y RonCAL, M.E. (1998): "Reflexiones sobre la explotación de materias primas para la producción de artefactos de piedra tallada durante la Prehistoria reciente de Andalucía oriental: el caso de los Castillejos (Montefrío, Granada)". En J. Bosch, X. Terradas y T. Orozco (eds.): Actes de la 2 a reunió de treball sobre aprovisionament de recursos lítics a la Prehistòria. Rubricatum 2: $161-170$.

Masson, A. (1984): "Un point de technologie chasséenne". Nouvelles de l'Archéologie du Musée d'Histoire Naturelle de Lyon 22: 31-42.

Mestres, J. (1988-1989): "Les sepultures neolítiques de l'Hort d'en Grimau (Castellví de la Marca, Alt Penedès)". Olerdulae 1-4: 97-129.

Mestres, J. y Martín, A. (1996): "Calibración de las fechas radiocarbónicas y su contribución al estudio del Neolítico catalán". En AA.VV.: I Congrés del Neolític a la Península ibèrica (Gavà-Bellaterra 1995). Rubricatum 1 (II): 791-804.

Molist, M.; Cruells, W. y Castells, J. (1987): "L'àrea megalítica de Tavertet (Osona)". Cota Zero 3: 5568.

Moss, E.H. (1983): The functional analysis of flint implements. Pincevent and Pont d'Ambon: Two case studies from the French Final Palaeolithic. BAR International Series 177. Hadrian Books Ltd. Oxford.

MuÑoz, A.M. (1965): La cultura neolítica catalana de los "Sepulcros de Fosa". Publicaciones eventuales 9. Instituto de Arqueología y Prehistoria de la Universidad de Barcelona. Barcelona.

Pelegrín, J. (1984a): “Approche technologique expérimentale de la mise en forme de nucléus pour le débitage systématique par pression". En AA.VV.: Économie du débitage laminaire. Préhistoire de la pierre taillée 2. Cercle de recherches et d'études préhistoriques. Meudon: 93-103.

- (1984b): "Systèmes expérimentaux d'immobilisation du nucléus pour le débitage par pression". En AA.VV.: Économie du débitage laminaire. Préhistoire de la pierre taillée 2. Cercle de recherches et d'études préhistoriques. Meudon: 105-116.

- (1984c): "Débitage par pression sur silex: nouvelles expérimentations". En AA.VV.: Économie du débitage laminaire. Préhistoire de la pierre taillée 2. Cercle de recherches et d'études préhistoriques. Meudon: $117-$ 127.

- (1988): "Débitage expérimental par pression: ‘du plus petit au plus grand" ". En AA.VV.: Technologie préhistorique. Notes et monographies techniques 25 . Éditions du CNRS. Paris: 37-53.

Perlès, C. (1977): Préhistoire du feu. Masson. Paris.

- (1992): "In search of lithic strategies. A cognitive approach to prehistoric chipped stone assemblages". En J.C. Gardin y C.S. Peebles (eds.): Representations in Archaeology. Indiana University Press. Boomington e Indianapolis: 223-247.

Plisson, H. (1987): "L'emmanchement dans l'habitation núm. 1 de Pincevent". En D. Stordeur (dir.): La main et l'outil: manches et emmanchements préhistoriques. Travaux de la Maison de l'Orient 15. Maison de l'Orient méditerranéen. Lyon: 75-88.

Pou, R.; Martí, M.; Bordas, A.; Díaz, J. y Martín, A. (1996): "La cultura de los "sepulcros de fosa" en el Vallès. Los casos particulares de Bòbila Madurell y Cámí de Can Grau (Sant Quirze del Vallès y La Roca del Vallès, Barcelona)". En AA.VV.: I Congrés del Neolític a la Península ibèrica (Gavà-Bellaterra 1995). Rubricatum 1 (II): 519-526.

PuRdy, B.A. y CLARK, D.E. (1979): "Weathering of thermally altered prehistoric stone implements". Lithic Technology 8 (2): 20-21.

RICK, J.W. (1978): Heat-altered cherts of the lower Illinois valley: an experimental study in prehistoric technology. Northwestern University Archaeological Program Prehistoric Records 2. Evanston.

RICK, J.W. y CHAPPELL, S. (1983): "Thermal alteration of silica materials in technological and functional perspective". Lithic Technology 12 (3): 69-80.

RipOLL, E. y LLONGUERAS, M. (1963): "La cultura neolítica de los sepulcros de fosa en Cataluña". Ampurias XXV: $1-90$.

Rodríguez, A.C.; Martín, D.; Cámalich, M.D. y González, P. (1996): "Las actividades tecnoeconómicas en "Cueva del Toro" (Antequera, Málaga) a través del análisis funcional". En AA.VV.: I Congrés del Neolític a la Península ibèrica (Gavà-Bellaterra 1995). Rubricatum 1 (I): 161-167.

TARRADELl, M. (1960): "La cultura de los sepulcros de fosa de Cataluña y el problema de sus relaciones con Valencia y Almería". Revista de la Facultad de Filosofía y Letras de la Universidad de Valencia: 1-21.

TARrús, J. (1987): “El megalitisme de l'Alt Empordà (Girona): els constructors de dòlmens entre el Neolític Mitjà i el Calcolític a l'Albera-Serra de Rodes-Cap de Creus". Cota Zero 3: 36-54.

TERradas, X. (1995): Las estrategias de gestión de los recursos líticos del Prepirineo catalán en el $I X^{\circ}$ milenio BP: el asentamiento prehistórico de la Font del Ros

T. P., 59, n. ${ }^{\circ} 1,2002$ 
(Berga, Barcelona). Treballs d'Arqueologia 3. Universitat Autònoma de Barcelona.

- (1996): La gestió dels recursos minerals entre les comunitats caçadores-recol-lectores: vers una representació de les estratègies de proveïment de matèries primeres. Tesis doctoral. Universitat Autònoma de Barcelona.

- (1998): "La gestión de los recursos minerales: propuesta teórico-metodológica para el estudio de la producción lítica en la Prehistoria”. En J. Bosch; X. Terradas y T. Orozco (eds.): Actes de la 2 a reunió de treball sobre aprovisionament de recursos lítics a la Prehistòria. Rubricatum 2: 21-28.

Terradas, X. y Gibaja, J.F. (2001): "El tratamiento térmico en la producción lítica: el ejemplo del Neolítico medio catalán". Cypsela 13: 29-56.

TEXIER, P.J. (1982): "Le débitage par pression pectorale à la béquille: une approche expérimentale au plus près des paramètres à l'origine de la rupture fragile des roches dures". En D. Cahen (ed.): Tailler! pour quoi faire. Studia Praehistorica Belgica 2. Musée royal de l'Afrique centrale. Tervuren: 57-64.

- 1983: "Un débitage expérimental de silex par pression pectorale à la béquille". Bulletin de la Société Préhistorique Française 81 (1): 25-27.

- 1984: "Le débitage par pression et la mécanique de la rupture fragile: initiation et propagation des fractures". En AA.VV.: Économie du débitage laminaire. Préhistoire de la pierre taillée 2. Cercle de recherches et d'études préhistoriques. Meudon: 139-147.

- Tixier, J. (1984): "Le débitage par pression". En
AA.VV.: Économie du débitage laminaire. Préhistoire de la pierre taillée 2. Cercle de recherches et d'études préhistoriques. Meudon: 57-70.

TORRENCE, R. (1984): "Towards an economic approach to pressure blade technology". En AA.VV.: Économie du débitage laminaire. Préhistoire de la pierre taillée 2. Cercle de recherches et d'études préhistoriques. Meudon: 159-166.

VAQUer, J. (1990): Le Néolithique en Languedoc occidentale. Éditions du CNRS. Paris.

Vignaud, A. (1995): "L'occupation néolithique dans la cuvette de Caramany, moyenne vallée de l'Agly (P.O.). Première approche". En AA.VV.: Cultures i medi. De la prehistòria a l'edat mitjana (Homenatge al professor Jean Guilaine). Institut d'Estudis Ceretans. Puigcerdà (Girona): 291-297.

Villalba, M.J.; Bañolas, L.; Arenas, J. y Alonso, M. (1986): Les mines neolítiques de Can Tintorer, Gavà. Excavacions 1978-1980. Excavacions arqueològiques a Catalunya, 6. Generalitat de Catalunya. Barcelona.

VOLKOV, P.V. y GUIRIA, E.I. (1991): "Recherche expérimentale sur une technique de débitage". En AA.VV.: 25 ans d'études technologiques en Préhistoire. Bilan et perspectives. Éditions APDCA. Juan-les-Pins: 379390.

Zilhão, J. y CARvalho, A.F. (1996): "O Neolítico do Maciço calcário estremenho. Crono-estratigrafia e povoamento". En AA.VV.: I Congrés del Neolític a la Península ibèrica (Gavà-Bellaterra 1995). Rubricatum 1 (II): 659-671. 